03

\title{
Механические эффекты в вихревом устройстве с вращающимся сердечником
}

\author{
(C) В.Н. Самохвалов
}

Самарский национальный исследовательский университет им. академика С.П. Королева

E-mail: vn_samokhvalov@mail.ru

Поступило в Редакцию 13 декабря 2016 г.

Исследован процесс возникновения вынужденного вращения осевого сердечника, установленного в модифицированной вихревой трубе, в направлении, противоположном вращению воздушного вихря и прецессии его оси. Установлено, что в процессе вращения металлического осевого сердечника возникает его динамический изгиб, приводящий к механическому износу его концевой части и излому в зоне закрепления в подшипнике, без остаточного искривления оси сердечника. Возбуждение вращения и наблюдавшиеся силовые эффекты не связаны с механическим воздействием вращающегося потока воздуха на осевой сердечник.

DOI: 10.21883/PJTF.2017.09.44581.16600

Изучению вихревого эффекта Ранка-Хилша посвящены многочисленные теоретические и экспериментальные исследования, подробно рассмотренные в [1]. До настоящего времени нет единого мнения о физическом механизме этого явления. В большинстве работ исследуется механизм разделения закрученного потока на охлажденное ядро и горячие периферийные слои, а также термогазодинамические параметры устройств, реализующих вихревой эффект. Экспериментально установлено наличие в закрученных потоках трехмерных вихревых структур винтовой формы и значительное влияние прецессии вихревого ядра на процесс энергоразделения [2].

Кроме эффекта энергоразделения в вихревых устройствах наблюдаются механические эффекты, не находящие очевидного объяснения. В работе [3] отмечен эффект вращения металлической оси, введенной в вихревой охладитель, в направлении, противоположном вращению воздушного вихря частотой вращения около $50 \mathrm{~Hz}$. В работе [4] показано, что вращающиеся в противоположном направлении предметы цилин- 


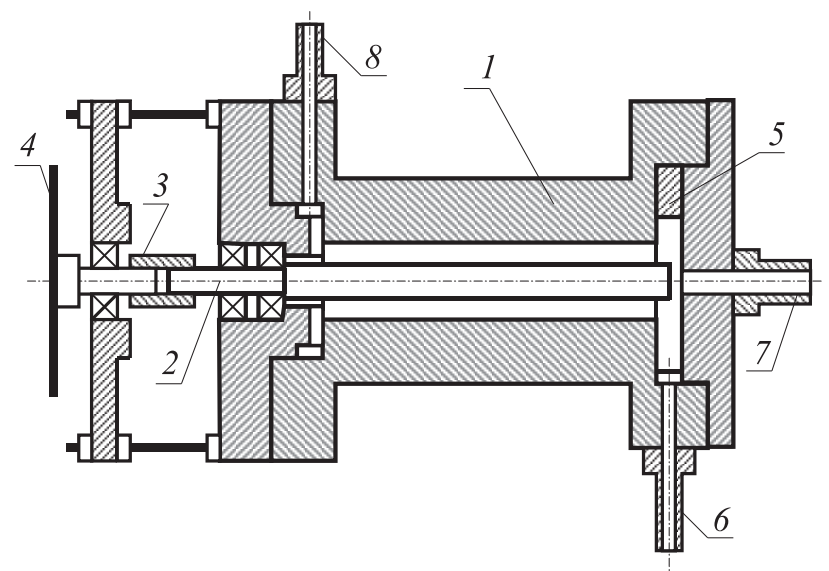

Принципиальная схема вихревого устройства.

дрической формы медленно прецессируют в направлении, совпадающем с направлением потока, а частота вращения зависит от давления на входе. При этом установлено, что тангенциальные составляющие скоростей вращения периферийного и осевого вихря вихревой трубы направлены в одну сторону [1], т. е. не меняют направления.

Для экспериментального исследования вышеуказанного эффекта было использовано вихревое устройство на базе противоточной вихревой трубы, принципиальная схема которого представлена на рисунке.

Внутри камеры расширения 1 вихревой трубы был установлен осевой металлический сердечник 2, имеющий возможность свободного вращения на двух подшипниках качения. Длина консольной части сердечника внутри вихревой трубы $-87 \mathrm{~mm}$. Через эластичную втулку 3 сердечник связан с диском 4, вращающимся на шарикоподшипнике. Эластичная втулка 3 была использована для минимизации вибрации измерительного диска 4 в процессе работы вихревого устройства. На диске 4 была установлена отражающая полоса для измерения скорости вращения осевого сердечника бесконтактным (лазерным) цифровым тахометром Mastech MS6208B. Вход вихревой трубы - улиточный, толщина „улитки“ 5 равна $2.5 \mathrm{~mm}$. Внутренний диаметр цилиндрической камеры расширения вихревой трубы равен $10 \mathrm{~mm}$, а ее длина составляет $76 \mathrm{~mm}$.

Письма в ЖТФ, 2017, том 43, вып. 9 
На входной штуцер 6 вихревой трубы (см. рисунок) подавалось давление из сети сжатого воздуха $P_{I}=0.1-0.6 \mathrm{MPa}$. Измерение температуры выходящего из вихревой трубы охлажденного и нагретого воздуха производилось с использованием двух мультиметров Mastech MY64, концы штатных термопар которых устанавливались внутри резиновых трубок, надетых на штуцер охлажденного воздуха 7 и штуцер нагретого воздуха 8 .

В экспериментах использовались металлические осевые сердечники диаметром 4.0, 5.0 и $6.0 \mathrm{~mm}$, изготовленные из гладких калиброванных прутков малоуглеродистой стали.

Проведенные эксперименты показали, что при установке осевого сердечника диаметром $6 \mathrm{~mm}$ и давлении воздуха на входе $P_{I} \sim 0.1 \mathrm{MPa}$ наблюдается неустойчивое (рывками) вынужденное вращение сердечника в направлении, противоположном вращению воздушного вихря, задаваемого улиточным входом.

При увеличении давления воздуха на входе вихревого устройства до $P_{I}=0.6 \mathrm{MPa}$ частота вращения осевого сердечника возрастала до $100-150 \mathrm{~Hz}$ в направлении, противоположном вращению воздушного вихря.

При установке сердечников диаметром 5 и $4 \mathrm{~mm}$ частота вращения была ниже. Максимальная скорость вращения при $P_{I}=0.6 \mathrm{MPa}$ достигала порядка 65 и $50 \mathrm{~Hz}$ соответственно, а неустойчивое вынужденное вращение сердечника начиналось только при давлении воздуха $P_{I}=0.12-0.15 \mathrm{MPa}$.

Использовавшаяся конструкция вихревого устройства с улиточным входом позволяла задавать как правовинтовое, так и левовинтовое вращение вихря (за счет переворачивания или смены „улитки“). Проведенные эксперименты показали, что в обоих случаях вынужденное вращение осевого металлического стержня происходит в направлении, противоположном вращению воздушного вихря. Таким образом экспериментально подтвержден эффект вращения металлической оси, установленной в вихревом устройстве, в направлении, противоположном вращению воздушного вихря, ранее отмеченный в работах $[3,4]$.

При этом если осевой выход охлажденного воздуха 7 (см. рисунок) в процессе работы вихревой трубы перекрывался, то частота вращения осевого сердечника не изменялась. Если перекрывался выход нагретого воздуха 8 (см. рисунок), то частота вращения осевого сердечника снижалась: до 50\% при давлении на входе вихревой трубы

Письма в ЖТФ, 2017, том 43, вып. 9 
$P_{I}=0.25-0.3 \mathrm{MPa} ;$ на $10-20 \%$ при давлении $P_{I}=0.5-0.6 \mathrm{MPa}$. Это можно объяснить уменьшением длины зоны взаимодействия вихря с осевым сердечником. При этом направление вращения сердечника в обоих случаях не изменялось, оно было противоположным вращению воздушного вихря.

Проведенные эксперименты показали также, что при вынужденном вращении сердечников возникают силы и моменты, приводящие к прецессии оси стержня и сильному его изгибу в процессе вращения. Это вызывало механический контакт концевой части сердечника с внутренней поверхностью камеры расширения вихревой трубы.

В экспериментах с металлическим сердечником диаметром $4 \mathrm{~mm}$ боковой зазор между сердечником и поверхностью камеры расширения вихревой трубы составлял $3 \mathrm{~mm}$, что исключало механический контакт сердечника с поверхностью камеры расширения при его упругом изгибе и люфта в подшипниках. Однако, как показали эксперименты, металлический консольно установленный на двух шарикоподшипниках сердечник „затачивается“ на конус за счет трения о внутреннюю поверхность камеры расширения вихревой трубы при его вынужденном вращении в течение нескольких минут. Длина образованного конического участка составляла около $15 \mathrm{~mm}$ при длине консольной части $87 \mathrm{~mm}$. В результате диаметр сердечника на его конце был равен $3.3 \mathrm{~mm}$ при исходном диаметре $4.0 \mathrm{~mm}$. При использовании осевых сердечников диаметром 5 и $6 \mathrm{~mm}$ их вынужденное вращение приводило к образованию блестящего пояска длиной $12-13 \mathrm{~mm}$ на его свободном конце. Такой характер механического износа концевой части осевого сердечника возможен только за счет касания им стенок камеры, при S-образном изгибе и прецессии оси сердечника в процессе его вынужденного вращения.

При этом остаточной деформации (искривления) оси сердечников не наблюдалось - ось сердечников после остановки вращения оставалась прямолинейной. Это свидетельствует о том, что в процессе вынужденного вращения сердечника имел место значительный динамический изгиб, не связанный с пластической деформацией материала.

Явления, подобные прецессии оси осевого сердечника - пульсации потока (типа прецессии), в вихревых трубах экспериментально зафиксированы [2]. Прецессия ядра вихря в вихревой трубе Ранка-Хилша и прецессия оси сердечника в использованном вихревом устройстве, очевидно, имеют одну физическую природу.

Письма в ЖТФ, 2017, том 43, вып. 9 
Наблюдаемое при визуализации течений в вихревых трубах направление прецессионного вращения вихревого ядра совпадает с направлением вращения самого вихря. Это дает основание предположить, что в описанных выше экспериментах механический износ конца сердечника происходил в процессе, когда направление вращения сердечника вокруг его оси и направление прецессии оси были противоположными.

Силы и моменты, возникающие в процессе вынужденного вращения и прецессии оси сердечника, неоднократно приводили к поломке сердечников диаметром 5 и $6 \mathrm{~mm}$ без искривления их оси. Излом сердечника происходил в зоне ступенчатого перехода сердечника к хвостовику для установки подшипников (диаметр $4.0 \mathrm{~mm}$ ), несмотря на предварительную обработку зоны перехода для удаления концентраторов напряжений. Излом сердечника имел вид, характерный для малоцикловой усталости при изгибе с кручением - многочисленные очаги начального разрушения в тонком поверхностном слое и зона долома в центральной части, с зернистой поверхностью. Это означает, что осевой сердечник в процессе вынужденного вращения претерпевал сильный циклический изгиб при напряжениях в материале, близких к пределу текучести материала.

Как показали измерения, при работе вихревого устройства с установленным осевым сердечником механизм разделения потоков на нагретый и охлажденный (эффект Ранка-Хилша) практически не наблюдается. С ростом давления на входе вихревого устройства происходило небольшое охлаждение воздуха на обоих входах 7 и 8 (см. рисунок). При $P_{I}=0.6 \mathrm{MPa}$ снижение температуры составляло $2-3^{\circ} \mathrm{C}$ относительно температуры воздуха на входе, что очевидно обусловлено обычным дросселированием потока. При удалении осевого сердечника устройство работало как обычная вихревая труба. При температуре воздуха на входе в вихревую трубу $T_{I}=+24^{\circ} \mathrm{C}$, при $P_{I}=0.6 \mathrm{MPa}$, температура охлажденного и нагретого воздуха составляла соответственно $T_{C}=-13^{\circ} \mathrm{C}, T_{H}=+37^{\circ} \mathrm{C}$.

Было проведено исследование влияния вынужденного вращения осевого сердечника и его торможения на температуру выходящего воздуха. Первоначально измерялась температура воздуха на выходах 7 и 8 вихревого устройства при механически остановленном сердечнике. Затем измерялась температура на выходах 7 и 8 в режиме вынужденного вращения осевого сердечника. Установлено, что переход к вынужденному вращению осевого сердечника приводит к снижению температуры

Письма в ЖТФ, 2017, том 43, вып. 9 
воздуха на выходе 7 на $2-3.5^{\circ} \mathrm{C}$ и к снижению температуры воздуха на выходе 8 на $1-1.5^{\circ} \mathrm{C}$. Снижение температуры выходящего воздуха на обоих выходах может свидетельствовать о том, что энергия воздушного вихря расходуется на вынужденное вращение осевого сердечника, несмотря на то, что они имеют противоположные направления вращения.

В статье [5] высказано предположение, что эффект противовращения осевого стержня, отмеченный в [3,4], обусловлен изменением знака внутренних моментных напряжений (моментной среды) вблизи оси вихревой трубы, но обоснования этого не приведено.

В проведенных экспериментах воздух вращается в небольшом $(2-3 \mathrm{~mm})$ зазоре между сердечником и стенкой камеры вихревой трубы. Вращение вихря задано входной „улиткой“, и оно измениться не может. Результаты экспериментов свидетельствуют о том, что вынужденное вращение осевого сердечника не обусловлено механическим воздействием вращающегося потока воздуха на осевой сердечник, так как оно противоположно направлению вращения вихря. Крутящие и изгибающие моменты, действовавшие на осевой сердечник в процессе вынужденного вращения, которые приводили к поломке сердечника и „затачиванию“ его концевого участка, не могут быть объяснены воздействием вихревого потока на сердечник.

Установленный эффект может объяснить сильное закручивание и изгиб объектов в вихревых процессах, например, в торнадо, которые не могут возникнуть вследствие простого высокоскоростного напора потока воздуха.

\section{Список литературы}

[1] Гуцол А.Ф. // УФН. 1997. Т. 167. В. 6. С. 665-687.

[2] Ахметов Ю.М., Зангиров Э.И., Свистунов А.В. // Труды МФТИ. 2014. Т. 6. B. 2 (22). C. $99-104$.

[3] Финько В.Е. // ЖТФ. 1983. Т. 53. В. 9. С. 1770-1776.

[4] Kolomiets S.M., Vasiljev V.I., Visheratin K.N., Zarenkov A.A. // International conference "Fluxes and Structures in Fluids". Sanct Petersburg, June 23-26. 2003. P. 92-93.

[5] Трофимов В.М. // Письма в ЖТФ. 2000. Т. 72. В. 5. С. 366-370.

Письма в ЖТФ, 2017, том 43, вып. 9 